\title{
Study on Vibration of Offshore Oil Field WHPA Platform
}

\author{
Gao Yong \\ CNOOC Energy Development co., Ltd. Tianjin, China
}

\section{Email address:}

gaoyong@cnooc.com.cn

\section{To cite this article:}

Gao Yong. Study on Vibration of Offshore Oil Field WHPA Platform. Science Discovery. Vol. 7, No. 5, 2019, pp. $278-285$. doi: 10.11648/j.sd.20190705.14

Received: August 6, 2019; Accepted: October 17, 2019; Published: October 23, 2019

\begin{abstract}
LD32-2 Oilfield is a margin Oilfield. In order to reduce structural steel quantity and cost. The out-transportation of crude oil adopts the scheme that uses an oil tanker berthing an offshore production and storage platform. This paper introduces the general design of the berthing scheme. Tanker mooring force, tanker impact force and tanker berthing model test. It illustrates the detection and analysis on the production platform and wellhead platform vibration during berthing, puts forward the temporary countermeasure and the two permanent countermeasure schemes and economic comparison.
\end{abstract}

Keywords: Produce Storage Oil Platform, Collision Force, Oil Tanker Docking, Platform Vibration, Solutions

\section{海上油田WHPA平台振动研究与实践}

高永

中海油能源发展股份有限公司, 天津, 中国

\section{邮箱}

gaoyong@cnooc.com.cn

摘要: LD32-2油田是边际油田。为减少结构用钢量, 降低投资费用等, 确定原油外输采用油轮直接靠泊生产储油平台 的方案。介绍了靠泊方案总体设计及分析、系泊操作环境条件的船模试验及系泊限制环境条件、油轮靠泊平台振动的 位移和力学监测分析、解决平台振动的临时措施设计及监测、永久性措施的技术方案及费用比对等内容。重点论述通 过油轮靠泊分析、系泊分析理论计算、油轮靠泊模型试验, 得出油轮靠泊生产储油平台产生的撞击力及系泊平台时的 撞击力、系缆力, 并由此确定油轮靠泊的限制条件; 通过现场实测数据分析油轮靠泊对平台造成的振动, 制订应对措 施等。

关键词: 生产储油平台, 撞击力, 油轮靠泊, 平台振动, 解决方案

\section{1. 绪论}

\section{1. 海上油田背景介绍}

LD32-2油田位于渤海东部海域, 油田由1座 4 腿井口 平台 (WHPA)、1座 8 腿生产储油平台（PSP）、2座系 缆平台 (MOP) 组成。PSP平台南侧设有油轮靠泊装置,
原油外输采用穿梭油轮直接靠泊PSP平台型式, WHPA 与PSP通过上下两座栈桥连接。

油田外输使用双壳双底的5000吨穿梭油轮, 在靠泊平 台时, 依靠系泊系统将其固定在平台一边。为了防止油轮 与平台的撞击损坏平台及油轮, 在PSP平台靠船一侧设置 了靠船件, 同时在靠船件侧面设置了V型橡胶护舷(图1), 以减少撞击力。 


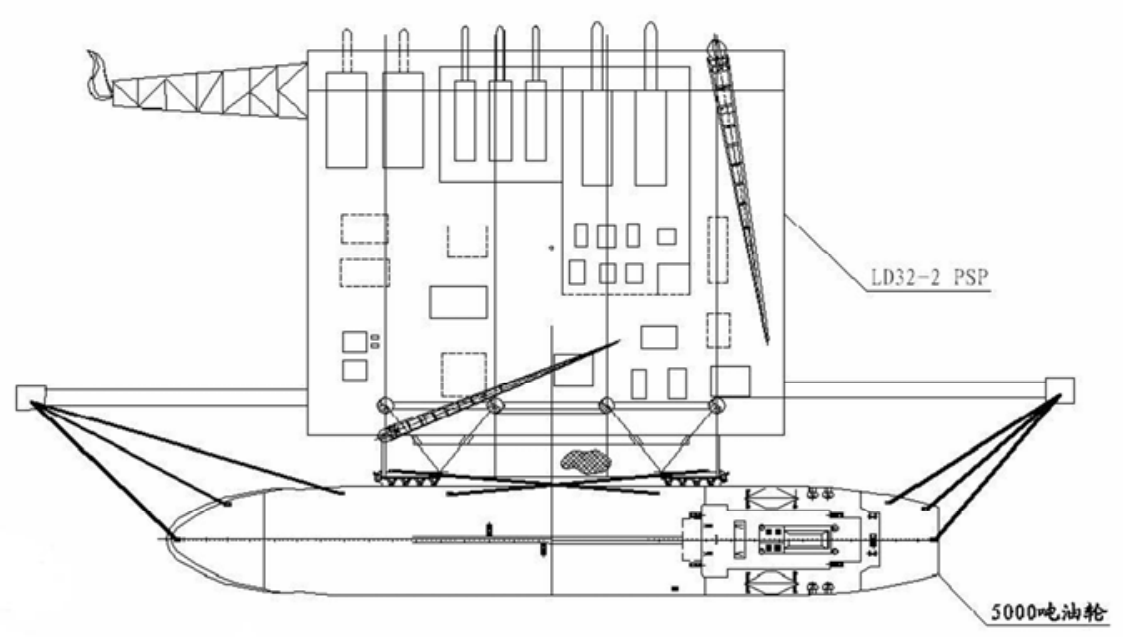

图1 油轮靠泊平台侧视图。

\section{2. 海上油田WHPA平台振动}

是年油田投产，产能为2100-2200方/天，较ODP提高 了 $50 \%$, 外输周期为 2.5 天。同年 10 月到过年 4 月, 渤海海 域气候环境较为恶劣, 在此期间, 油田共计外输作业 87 次, 超出限制海况条件作业次数 59 次, 占外输作业总数的 $68 \%$ 。油轮超限制海况条件进行靠泊作业时, WHPA平台 振动较大, 对WHPA平台钻井作业造成影响, 并对平台结 构安全构成隐患。

\section{2. 靠泊方案设计}

\section{1. 设计背景}

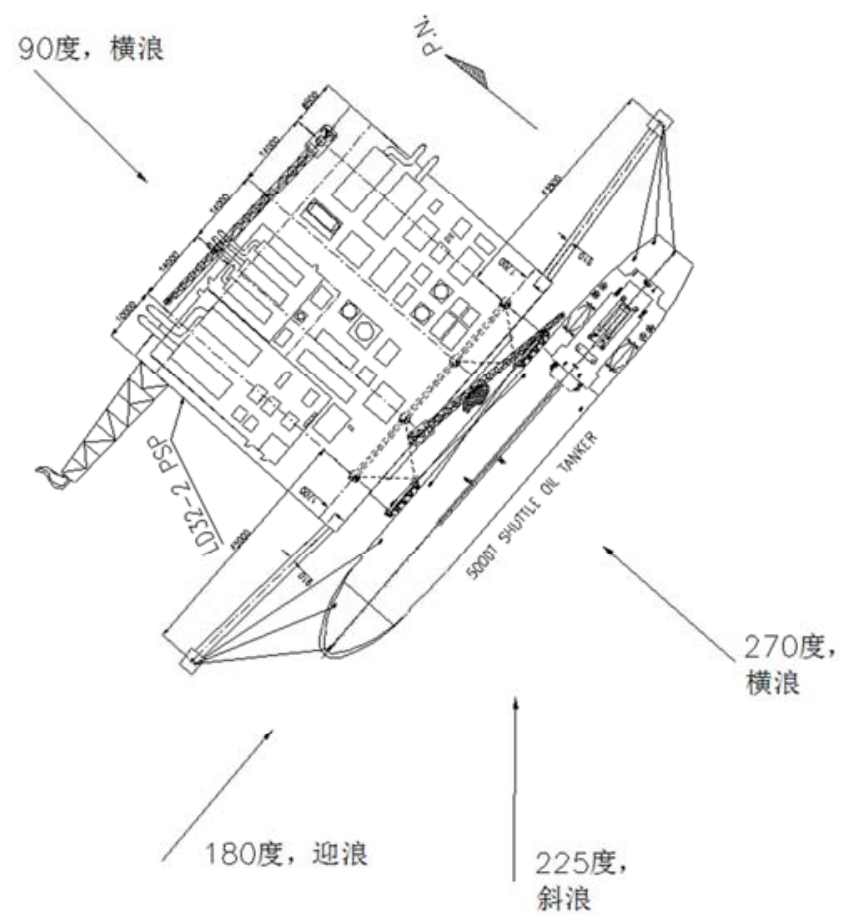

图2 油轮靠泊示意图。
LD32-2油田是边际油田, 开发收益较低。在项目前期 研究阶段, 从减少结构用钢量, 降低投资费用等因素出发, 确定了直接靠泊生产储油平台方案。

采用 5000 吨级油轮进行原油外输作业。该油轮型长 $107.42 \mathrm{~m}$, 型宽 $15.00 \mathrm{~m}$, 型深 $7.49 \mathrm{~m}$, 设计吃水 $6.00 \mathrm{~m}$, 最 大吃水 $6.40 \mathrm{~m}$ 。靠泊示意图如图 (2) 所示:

\section{2. 理论分析}

穿梭油轮靠泊分析考虑了系缆力、靠船件橡胶护舷撞 击力、船体舫侧结构和平台结构强度 [1]。

\subsection{1. 靠泊分析}

在前期研究中, PSP平台采用 10 个DA-A $800 \times 2.5 \mathrm{~m}$ 高 反力型橡胶护舷, 5 个为一组, 分列在靠船件东西两侧。 设计压缩变形为 $52.5 \%$ 时, 吸能值为 $558 \mathrm{~kJ}$, 所对应的反力 值为 $166 \mathrm{t}$ 。最大压缩变形为 $55 \%$ 时, 吸能值为 $598 \mathrm{~kJ}$, 所对 应的反力值为 $237 \mathrm{t}$ 。

船舶靠泊时的有效撞击能根据API RP 2A-WSD规范 计算:

$$
E=0.5 \alpha m v^{2}
$$

式(1)中: E为船舶的动能 $(\mathrm{kJ}) ; \alpha$ 为附加质量系数, 舷侧撞击时, $\alpha=1.4$; 首/尾撞击时, $\alpha=1.1 ; \mathrm{m}$ 为船舶质 量 $(\mathrm{t})$ (油轮是以压载情况到平台装油, 所以 $\mathrm{m}$ 取压载排水 量); $\mathrm{V}_{\mathrm{n}}$ 为船舶靠岸的法向速度 $(\mathrm{m} / \mathrm{s})$ 。

分配在每个橡胶护舷的有效撞击能 $\mathrm{E}_{\mathrm{w}}$ 按《港口工程荷 载规范》计算:

$$
E_{w}=\frac{K}{n} E_{w o}
$$

式中: $E_{w}$ 为分配在每个墩上的有效撞击能; $E_{w 0}$ 为总 的撞击能; $N$ 为靠船墩数目, $n>4$ 时, 取 $n=4 ; K$ 为不均匀 系数 $(\mathrm{n}=4$ 时, 取 $\mathrm{K}=1.5 ; \mathrm{n}=2-3$ 时, 取 $\mathrm{K}=1.6-2.0$ )。

操作工况容许应力放大系数取 1.0 ; 临界工况容许应 力放大系数取 1.33 。 
(1)操作工况: 操作工况考虑了一定的安全系数, 橡胶 护舷吸能在曲线范围内。靠泊速度取 $0.5 \mathrm{~m} / \mathrm{s}$, 采用公式(1) 计算所得的撞击能为 $680 \mathrm{~kJ}$, 分配到每个护舷所承受的能 量采用公式(2)计算, 所得结果为 $255 \mathrm{~kJ}$ 。船靠泊时存在靠 泊角度, 不同的靠泊角度, 护舷受力大小不同, 护舷垂直 受压时吸能最大。

(2)临界工况: $\mathrm{DA}-\mathrm{A} 800 \mathrm{H} \times 2.5 \mathrm{~m}$ 型护舷最大吸能为 $598 \mathrm{~kJ}$, 根据这个最大吸能, 通过公式(1)、(2)可以反推出 护舷所允许的最大靠船速度为 $0.76 \mathrm{~m} / \mathrm{s}$ 。当船速 $\mathrm{v}=0.76 \mathrm{~m} / \mathrm{s}$, $0^{\circ}$ 靠泊时, 撞击能为 $1569.9 \mathrm{~kJ}$, 分配到每个护舷能量为 $1.5 \times 1569.9$

$\frac{1569.9}{4}=588.7 \mathrm{~kJ}$, 按照护舷的性能曲线查出反力值, 查 得每个护舷的反力为 $237 \mathrm{t}$ 。如果油轮速度超过 $0.76 \mathrm{~m} / \mathrm{s}$, 将 超过护舷的最大变形, 所产生的能量超过护舷的最大吸能, 故把 $0.76 \mathrm{~m} / \mathrm{s}, 0^{\circ}$ 靠泊作为 $5000 \mathrm{~T}$ 油轮靠泊时的橡胶吸能临 界工况。平台结构的强度可承受穿梭油轮以 $6.7 \mathrm{~m} / \mathrm{s}$ 航速撞 击, 靠船件在穿梭油轮 $2.0 \mathrm{~m} / \mathrm{s}$ 航速撞击时局部破坏 [2]。

\subsection{2. 系泊分析}

油轮系泊时, 系缆力采用MOSES软件计算, 撞击力 采用MOSES和经验公式两种方法分析, 系泊分析考虑了 压载和满载两种不同的工况。

(1)系缆力计算

前期研究中系缆绳采用直径为 $64 \mathrm{~mm}$ 的聚酯缆, 缆绳 破断力 $65 \mathrm{t}$ 。采用MOSES软件计算油轮在风, 浪, 流作用 下的系缆力, 得到操作工况如表(1)、(2)所示:

表1 压载工况限制条件。

\begin{tabular}{lll}
\hline 浪向角 & 浪高 & 系缆力 $(\mathbf{t})$ \\
\hline 迎浪 $\left(180^{\circ}\right)$ & $2.5 \mathrm{~m}$ & 35 \\
斜浪 $\left(225^{\circ}\right)$ & $1.5 \mathrm{~m}$ & 33 \\
横浪 $\left(270^{\circ}\right)$ & $1.0 \mathrm{~m}$ & 42 \\
横浪 $\left(90^{\circ}\right)$ & $1.5 \mathrm{~m}$ & 49 \\
\hline
\end{tabular}

表2 满载工况限制条件。

\begin{tabular}{lll}
\hline 浪向角 & 浪高 & 系缆力 $(\mathbf{t})$ \\
\hline 迎浪 $\left(180^{\circ}\right)$ & $3.5 \mathrm{~m}$ & 52 \\
斜浪 $\left(225^{\circ}\right)$ & $3.0 \mathrm{~m}$ & 52 \\
横浪 $\left(270^{\circ}\right)$ & $2.0 \mathrm{~m}$ & 56 \\
横浪 $\left(90^{\circ}\right)$ & $1.0 \mathrm{~m}$ & 57 \\
\hline
\end{tabular}

(2)撞击力计算

油轮的撞击力采用MOSES软件和经验公式两种方法 进行了计算。

MOSES分析, 所选的橡胶护舷达到最大吸能时, 产 生的反力值为 $170 \mathrm{t}$ 。MOSES 软件计算得到的油轮压载和满 载情况下斜浪和横浪时撞击力小于 $170 \mathrm{t}$, 最大反力的限制 条件如表(3)、(4)所示:

\section{表3 压载工况限制条件。}

\begin{tabular}{lll}
\hline 浪向角 & 浪高 & 撞击力 $(\mathbf{t})$ \\
\hline 斜浪 $\left(225^{\circ}\right)$ & $2.0 \mathrm{~m}$ & 159 \\
横浪 $\left(270^{\circ}\right)$ & $1.0 \mathrm{~m}$ & 157 \\
\hline
\end{tabular}

表4 满载工况限制条件。

\begin{tabular}{lll}
\hline 浪向角 & 浪高 & 撞击力 $(\mathbf{t})$ \\
\hline 斜浪 $\left(225^{\circ}\right)$ & $2.5 \mathrm{~m}$ & 159 \\
横浪 $\left(270^{\circ}\right)$ & $1.0 \mathrm{~m}$ & 154 \\
\hline
\end{tabular}

经验公式计算, 只考虑波浪的影响, 横浪所产生的撞 击力最大, 故需计算油轮在横浪作用下的撞击力。系泊船 舶的有效撞击能量 $E_{w o}$ 按《系泊船舶在横浪作用下的撞击 能量》计算。公式如下:

$$
E_{o}=\frac{1}{2} k C_{m} M V_{b}^{2}
$$

式中: $\mathrm{k}$ 一偏心撞击能量折减系数; $\mathrm{C}_{\mathrm{m}}$ 一附加水体影 响系数; $\mathrm{M}$ 一船舶质量 $(\mathrm{t})$, 按船舶相应的排水量计算; $\mathrm{V}_{\mathrm{b}}$ 撞击的法向速度 $(\mathrm{m} / \mathrm{s})$ 。 $\mathrm{k}$ 为偏心撞击能量折减系数, 按 公式(4)计算:

$$
k=\frac{1}{1+\left(\frac{l}{r}\right)^{2}}
$$

式中 $l$ 表示船舶与码头撞击点(即护舷中心位置)到船 舶横剖面重心高程的垂距,

即偏心距; $r$ 为船舶横断面上的回转半径，按公式(5) 计算:

$$
r=\sqrt{\frac{I}{M}}
$$

式中I为船舶横向惯性矩(与船舶计算装载度相应)。

计算所得总的撞击能后, 分配到每个护舷上的撞击能

\begin{tabular}{|c|c|c|c|c|}
\hline \multirow[b]{2}{*}{ 有效波高 } & \multicolumn{2}{|l|}{ 压载 } & \multicolumn{2}{|l|}{ 满载 } \\
\hline & $\begin{array}{l}\text { 油轮总的撞 } \\
\text { 击能 (kJ) }\end{array}$ & $\begin{array}{l}\text { 单个橡胶 } \\
\text { 吸能 }(k J)\end{array}$ & $\begin{array}{l}\text { 油轮总的撞 } \\
\text { 击能 (kJ) }\end{array}$ & $\begin{array}{l}\text { 单个橡胶 } \\
\text { 吸能 }(\mathrm{kJ})\end{array}$ \\
\hline $0.5 \mathrm{~m}$ & 39 & 15 & 21 & 8 \\
\hline $1.0 \mathrm{~m}$ & 563 & 211 & 312 & 117 \\
\hline $1.5 \mathrm{~m}$ & 2496 & 936 & 1285 & 482 \\
\hline $2.0 \mathrm{~m}$ & 6936 & 2601 & 3571 & 1339 \\
\hline
\end{tabular}
按公式(2)进行计算, 结果详见表(5)。

表5 不同波高下船舶的撞击能 (kJ)。

由上表可知, 压载工况下, 当波高为 $1.5 \mathrm{~m}$ 时单个橡胶 吸能超过最大吸能值; 满载工况下, 当波高为 $2.0 \mathrm{~m}$ 时单个 橡胶吸能超过最大吸能值。

\section{3. 船模试验}

穿梭油轮直接靠泊平台在海油总范围内是首次应用, 其对海上操作环境条件有较为严格的限制, 因此, 需要通 过模型试验为工程设计和海上外输作业提供可靠的操作 环境条件。根据5000吨油轮靠泊模型试验[3], 根据试验结 果进行PSP平台结构和靠船件的设计。

(1)系缆力 
模型试验中选取缆绳破断力 $130 \mathrm{t}$, 取 1.5 安全系数, 则 设计破断载荷为 $130 / 1.5=86.7 \mathrm{t}$ 。通过试验得出不超过 $86.7 \mathrm{t}$ 系缆力对应环境条件如表(6)所示:

表6 船模试验不同工况系缆力值。

\begin{tabular}{llll}
\hline 工况 & 浪向角 $\left(^{\circ}\right)$ & 波高 $(\mathbf{m})$ & 系缆力 $(\mathbf{t})$ \\
\hline \multirow{4}{*}{ 满载 } & 90 & 1.0 & 56.3 \\
& 180 & 2.5 & 53.4 \\
& 225 & 1.5 & 68.4 \\
& 90 & 1.0 & 78.0 \\
压载 & 180 & 1.0 & 71.7 \\
& 225 & 2.0 & 77.0 \\
& 270 & 1.5 & 54.5 \\
\hline
\end{tabular}

(2)撞击力

根据油轮船体强度分析, 单个护舷最大反力为 $237 \mathrm{t}$ 。 通过试验得出不超过 237t撞击力对应环境条件如表(7)所 示:

表7 船模试验不同工况撞击力值。

\begin{tabular}{llll}
\hline 工况 & 浪向角 $\left(^{\circ}\right)$ & 波高 $(\mathbf{m})$ & 撞击力 $(\mathbf{t})$ \\
\hline \multirow{4}{*}{ 满载 } & 90 & 1.0 & 127.9 \\
& 180 & 3.5 & 214.7 \\
& 225 & 1.5 & 194.2 \\
& 270 & 0.5 & 156.5 \\
压载 & 90 & 1.0 & 148.0 \\
& 180 & 2.0 & 194.9 \\
& 225 & 1.5 & 171.0 \\
\hline
\end{tabular}

\section{4. 限制环境条件}

模型试验得出的结果需取两种工况并同时满足系缆 力和撞击力的要求, 所得限制环境条件见表(8):

表8 油轮靠泊限定环境条件。

\begin{tabular}{lll}
\hline 工况 & 速度 $(\mathbf{m} / \mathbf{s})$ & 波高 $(\mathbf{m})$ \\
\hline 靠泊速度 & 0.5 & - \\
横浪 $\left(90^{\circ}\right)$ & - & 1.0 \\
横浪 $\left(270^{\circ}\right)$ & - & 0.5 \\
斜浪 $\left(225^{\circ}\right)$ & - & 1.5 \\
迎浪 $\left(180^{\circ}\right)$ & - & 2.0 \\
\hline
\end{tabular}

\section{3. 平台振动分析}

采用监测仪器对海上油田WHPA平台振动进行测量, 并分析WHPA平台出现振动的原因, 为下一步采取措施减 缓WHPA平台振动[4]提供依据。

\section{1. 位移监测}

采用压电式加速度传感器、YE5858A双积分型电荷放 大器、DSP一32并口数据采集仪进行数据采集。

\subsection{1. 测点布置}

根据WHPA平台布置确定振动监测点布置图。对 WHPA至PSP平台的栈桥两端, WHPA平台及PSP平台分 别进行了位移的监测。测点布置图如图(3)所示:

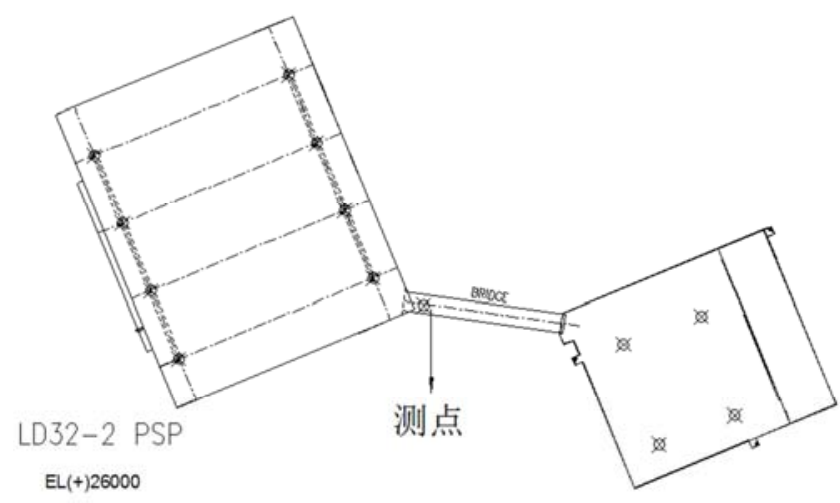

LD32-2 WHPA $E L(+) 25000$

图3 振动测点布置图。

\subsection{2. 数据分析}

在相似海况条件, 对有、无油轮外输的栈桥位移进行 数据分析[5]。无外输作业时, 栈桥振动数据如表(9)所示:

表9 无油轮外输时平台振动数据。

\begin{tabular}{|c|c|c|c|}
\hline 环境条件 & 工况 & 传感器位置 & 最大位移 $(\mathrm{mm})$ \\
\hline \multirow{3}{*}{$\begin{array}{l}\text { 靠 泊 浪 向 } \\
225^{\circ} \\
\text { 波高 } 2.0 \mathrm{~m}\end{array}$} & $\begin{array}{l}\text { 无 油 轮外 } \\
\text { 输 }\end{array}$ & $\begin{array}{l}\text { WHPA EL+25000 栈 } \\
\text { 桥端栈桥上垂直栈桥 } \\
\text { 走向 }\end{array}$ & 19.09 \\
\hline & $\begin{array}{l}\text { 无油轮外 } \\
\text { 输 }\end{array}$ & $\begin{array}{l}\text { PSP EL+26000 栈桥 } \\
\text { 端栈桥上Z轴方向 }\end{array}$ & 16.75 \\
\hline & $\begin{array}{l}\text { 无油轮外 } \\
\text { 输 }\end{array}$ & $\begin{array}{l}\text { PSP EL+26000 栈桥 } \\
\text { 端栈桥上 垂直栈桥 } \\
\text { 走向 }\end{array}$ & 6.04 \\
\hline
\end{tabular}

在油轮外输油作业时, 平台振动数据如表(10)所示:

表10 油轮外输时平台振动数据。

\begin{tabular}{llll}
\hline 环境条件 & 工况 & 传感器位置 & 最大位移 $(\mathbf{m m})$ \\
\hline & & WHPA EL+25000 栈 & \\
& 油轮外输 & 桥端 栈桥上 垂直栈 & 20.07 \\
& & 桥走向 & \\
& & PSP EL+26000 栈桥 & \\
靠 泊 浪 向 & & 油轮外输 & 端 栈桥上 Z 轴方 33.71 \\
$225^{\circ}$ & 向 & \\
波高 $2.0 \mathrm{~m}$ & & PSP EL+26000 栈桥 \\
& & & \\
& 油轮外输 & 端 栈桥上 垂直栈 & 9.97 \\
& & 桥走向 & \\
\hline
\end{tabular}

对比测试数据, 相似海况下同一测点, 在油轮靠泊时 位移较大。

\subsection{3. 监测结果}

通过对WHPA平台振动监测, 结论如下:

(1)WHPA平台振动主要是油轮靠泊PSP平台引起的。

(2)栈桥与 $\mathrm{PSP}$ 平台有 $60^{\circ}$ 夹角, 油轮撞击 $\mathrm{PSP}$ 平台导致 WHPA平台的扭转。

(3)WHPA平台是四腿导管架型式, 平台结构刚度偏小, 其上部组块重量较大。 


\section{2. 力学测试}

\subsection{1. 测试内容}

测定PSP两端靠船件上部分关键点的应变、应力, 采 用数值计算方法[6]确定靠船件在油轮系泊过程中的撞击 力。靠船件测点布置图如图(4)所示:

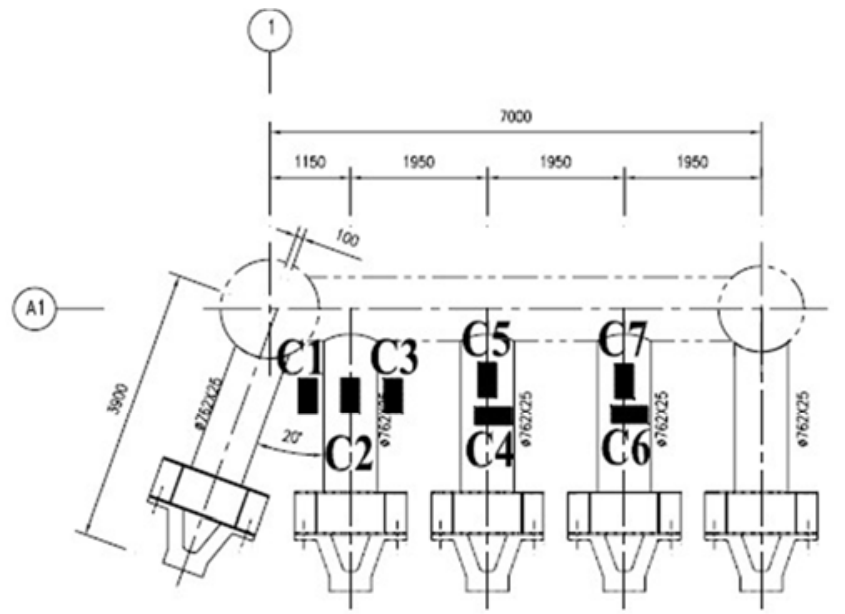

图4 单个靠船件测点布置示意图。

测定上下两座栈桥与WHPA平台连接处的应变、应力, 以确定栈桥对WHPA平台的作用力。栈桥测点布置如图(5)、 (6)所示:

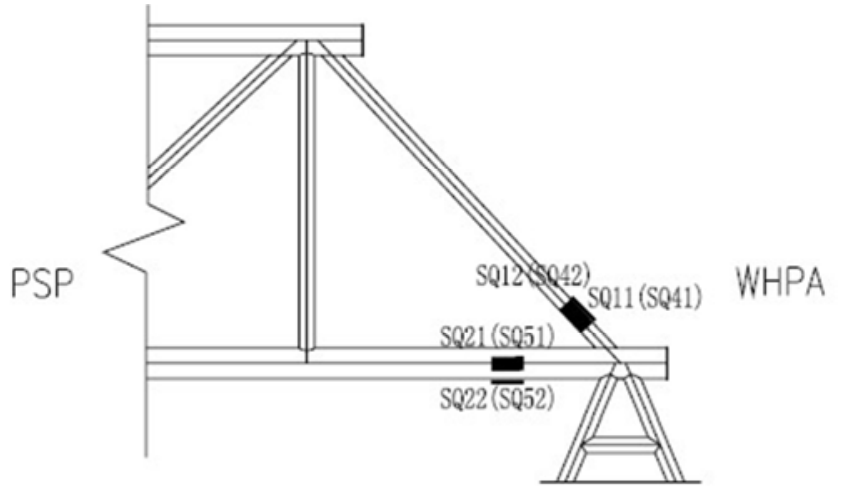

图5 上栈桥测点立面布置示意图。

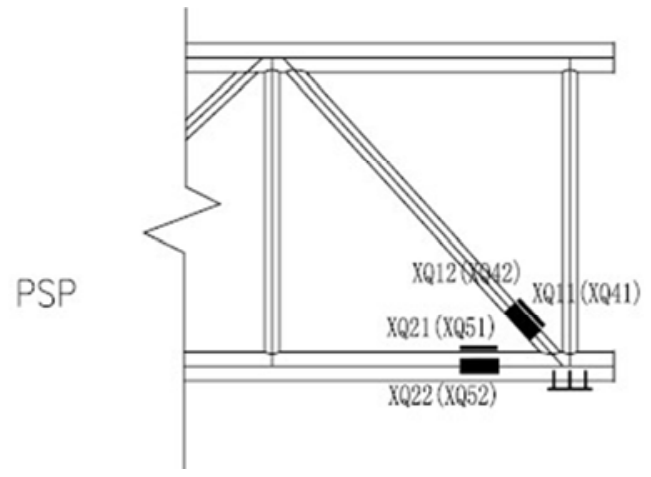

图6 下栈桥测点立面布置示意图。
测定栈桥管线上部分关键点的应变、应力, 确定管线 对WHPA 平台的作用力[7]。栈桥管线测点布置如表(11)、 (12)所示:

表11 上部管线测点布置。

\begin{tabular}{|c|c|c|c|c|}
\hline 管线编号 & 材质 & 输送介质 & 测点位置 & 测点编号 \\
\hline 12"-CR-1220-A1-HT28 & 碳钢 & 原油 & 管顶 & SG11 \\
\hline 12"-CR-1220-A1-HT28 & 碳钢 & 原油 & 管侧 & SG12 \\
\hline 4"-WF-4236-A4 & 不锈钢 & 淡水 & 管顶 & SG21 \\
\hline 4"-WF-4236-A4 & 不锈钢 & 淡水 & 管侧 & SG22 \\
\hline 3"-WF-4217-A4-HT5 & 不锈钢 & 淡水 & 管顶 & SG31 \\
\hline 3"-WF-4217-A4-HT5 & 不锈钢 & 淡水 & 管侧 & SG32 \\
\hline 11/2"-WT-4223-A4-HT5 & 不锈钢 & 技术水 & 管顶 & SG41 \\
\hline 11/2"-WT-4223-A4-HT5 & 不锈钢 & 技术水 & 管侧 & SG42 \\
\hline \multicolumn{5}{|c|}{ 表12 下部管线测点布置图。 } \\
\hline 管线编号 & 材质 & 输送介质 & 测点位置 & 测点编号 \\
\hline 14"-WS-4018-A7-HT5 & $\begin{array}{l}\text { 塑料钢骨架 } \\
\text { 复合管 }\end{array}$ & 海水 & 管顶 & XG11 \\
\hline 14"-WS-4018-A7-HT6 & $\begin{array}{l}\text { 塑料钢骨架 } \\
\text { 复合管 }\end{array}$ & 只 海水 & 管侧 & $\mathrm{XG12}$ \\
\hline 10"-WI-4101-E1-HT5 & 碳钢 & 注入水 & 管顶 & $\mathrm{XG} 21$ \\
\hline 10"-WI-4101-E1-HT5 & 碳钢 & 注入水 & 管侧 & $\mathrm{XG} 22$ \\
\hline 4"-PW-1201-A1-HT28 & 碳钢 & 注入水 & 管顶 & XG31 \\
\hline 4"-PW-1201-A1-HT28 & 碳钢 & 注入水 & 管侧 & XG32 \\
\hline 2"-HM-2004-B1-H & 碳钢 & 注入水 & 管顶 & XG41 \\
\hline 2"-HM-2004-B1-H & 碳钢 & 注入水 & 管侧 & XG42 \\
\hline
\end{tabular}

\subsection{2. 测试结果}

钢的弹性模量 $[8] \mathrm{E}=2.1 \times 10^{11} \mathrm{~Pa}$, 钢骨架复合材料的弹 性模量 $\mathrm{E}=2.1 \times 10^{10} \mathrm{~Pa}[5]$ 。通过测得的应变, 可计算作用力, 在油轮系泊过程中撞击力数据如表(13)所示:

表13 油轮撞击力统计表。

\begin{tabular}{lllll}
\hline 测试次数编号 & $\mathbf{1}$ & $\mathbf{2}$ & $\mathbf{3}$ & $\mathbf{4}$ \\
\hline 浪向角 $\left({ }^{\circ}\right)$ & 225 & 225 & 225 & 270 \\
波高 $(\mathrm{m})$ & 1.0 & 2.0 & 1.0 & 3.0 \\
东侧撞击力 $(\mathrm{t})$ & 477.5 & 613.1 & 346.4 & 668.2 \\
西侧撞击力 $(\mathrm{t})$ & 15.6 & 621.3 & 362 & 620.5 \\
\hline
\end{tabular}

栈桥作用力如表(14)所示:

表14 栈桥作用力表。

\begin{tabular}{llll}
\hline 测试次数编号 & $\mathbf{1}$ & $\mathbf{2}$ & $\mathbf{4}$ \\
\hline 浪向角 $\left({ }^{\circ}\right)$ & 225 & 225 & 270 \\
波高 $(\mathrm{m})$ & 1.0 & 2.0 & 3.0 \\
上栈桥南侧 $(\mathrm{t})$ & 9.0 & 10.1 & 11.7 \\
上栈桥北侧 $(\mathrm{t})$ & 12.9 & 14.2 & 16.6 \\
下栈桥南侧 $(\mathrm{t})$ & 8.0 & 8.8 & 10.2 \\
下栈桥北侧 $(\mathrm{t})$ & 11.2 & 12.3 & 14.2 \\
\hline
\end{tabular}

从上表可以看出, 栈桥南侧支座对WHPA平台的作用 力比北侧支座对WHPA平台的作用力小。上栈桥对WHPA 平台的作用力比下栈桥对WHPA平台的作用力稍大。

栈桥管线作用力如表(15)所示: 
表15 管线作用力表。

\begin{tabular}{llll}
\hline 测试次数编号 & $\mathbf{2}$ & $\mathbf{3}$ & $\mathbf{4}$ \\
\hline 浪向角 $\left({ }^{\circ}\right)$ & 225 & 225 & 270 \\
波高 $(\mathrm{m})$ & 2.0 & 1.0 & 3.0 \\
SG1 $(\mathrm{t})$ & 11.2 & 10.4 & 13.3 \\
SG2 $(\mathrm{t})$ & 3.5 & 2.7 & 3.8 \\
SG3 (t) & & 2.3 & 2.7 \\
SG4 (t) & & 0.9 & 1.1 \\
XG1 (t) & 1.3 & 1.1 & 1.3 \\
XG2 (t) & 21.0 & 20.2 & 23.5 \\
XG3 (t) & & 3.1 & 3.5 \\
XG4 (t) & & 1.4 & 2.1 \\
\hline
\end{tabular}

综上所述，靠船件、栈桥、栈桥管线上的作用力与油 轮靠泊的环境条件有关, 海况条件越差, 作用力越大。设 计护舷反力为 $237 \mathrm{t} \times 4=948 \mathrm{t}$, 所测的油轮撞击力在设计容许 范围内。

\section{4. 解决平台振动的实践}

为解决海上油田WHPA平台的振动。采用了临时性措 施减缓平台的振动, 并提出永久性方案。

\section{1. 临时性措施}

临时方案是在原 $\mathrm{V}$ 型护舷外侧安装靠球，可短时间内 解决海上油田WHPA平台振动问题。

\subsection{1. 方案设计}

方案选用 $\Phi=2.5 \mathrm{~m}, \mathrm{~L}=5.5 \mathrm{~m}$ 的充气靠球, 靠球安装在 PSP平台两组靠船件外侧, 靠球和原有靠船件V型橡胶护 舷共同缓冲 5000 吨油轮在靠泊以及系泊过程中对平台的 撞击力。靠球在PSP平台布置如图(7)所示:

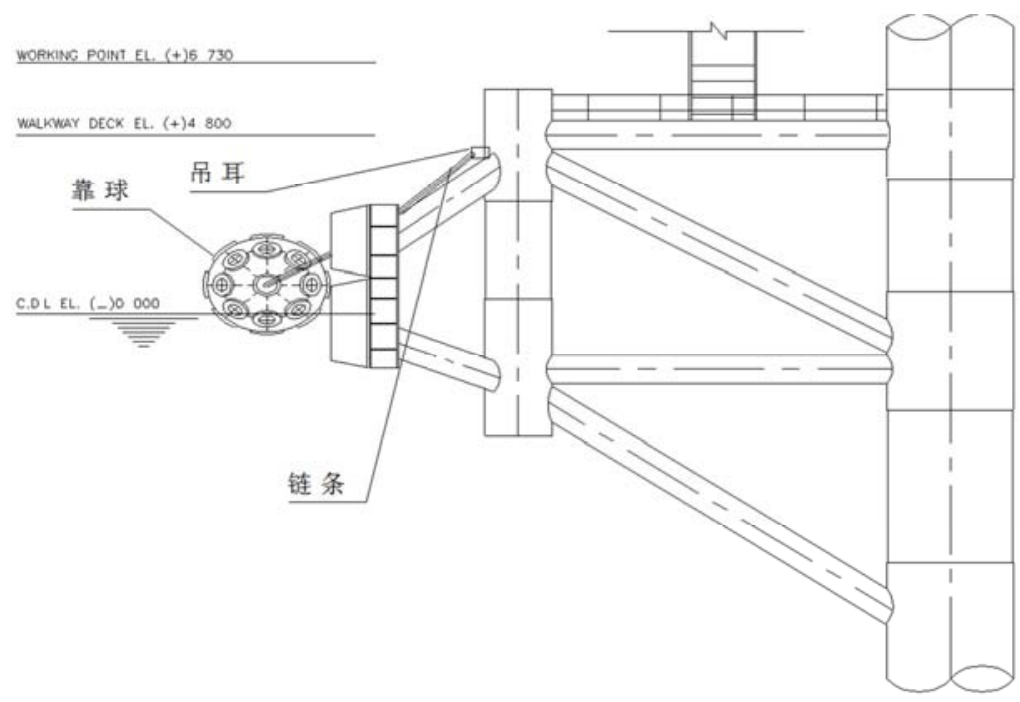

图7 靠球安装示意图。

\subsection{2. 效果}

靠球安装前后, PSP靠船件、栈桥及栈桥管线上所受 作用力对比如表(16)、(17)、(18)所示:

表16 油轮撞击力表。

\begin{tabular}{lllllll}
\hline 测试次数编号 & $\mathbf{1}$ & $\mathbf{2}$ & $\mathbf{3}$ & $\mathbf{4}$ & $\mathbf{5}$ & $\mathbf{6}$ \\
\hline 浪向角 $\left({ }^{\circ}\right)$ & 225 & 225 & 225 & 270 & 90 & 225 \\
波高 $(\mathrm{m})$ & 1.0 & 2.0 & 1.0 & 3.0 & 3.0 & 2.5 \\
是否安装靠球 & 否 & 否 & 否 & 否 & 是 & 是 \\
东侧撞击力 $(\mathrm{t})$ & 477.5 & 613.1 & 346.4 & 668.2 & 100.6 & 85.7 \\
西侧撞击力 $(\mathrm{t})$ & 15.6 & 621.3 & 362 & 620.5 & 114.7 & 265.9 \\
\hline
\end{tabular}

表17 栈桥作用力表。

\begin{tabular}{llllll}
\hline 测试次数编号 & $\mathbf{1}$ & $\mathbf{2}$ & $\mathbf{4}$ & $\mathbf{5}$ & $\mathbf{6}$ \\
\hline 浪向角 $\left({ }^{\circ}\right)$ & 225 & 225 & 270 & 90 & 225 \\
波高 $(\mathrm{m})$ & 1.0 & 2.0 & 3.0 & 3.0 & 2.5 \\
是否安装靠球 & 否 & 否 & 否 & 是 & 是 \\
上栈桥南侧 $(\mathrm{t})$ & 9.0 & 10.1 & 11.7 & 3.5 & 7.5 \\
上栈桥北侧 $(\mathrm{t})$ & 12.9 & 14.2 & 16.6 & 5.0 & 10.5 \\
下栈桥南侧 $(\mathrm{t})$ & 8.0 & 8.8 & 10.2 & 3.2 & 6.5 \\
下栈桥北侧 $(\mathrm{t})$ & 11.2 & 12.3 & 14.2 & 4.5 & 8.9 \\
\hline
\end{tabular}

表18 管线作用力表。

\begin{tabular}{llllll}
\hline 测试次数编号 & $\mathbf{2}$ & $\mathbf{3}$ & $\mathbf{4}$ & $\mathbf{5}$ & $\mathbf{6}$ \\
\hline 浪向角 $\left({ }^{\circ}\right)$ & 225 & 225 & 270 & 90 & 225 \\
波高 $(\mathrm{m})$ & 2.0 & 1.0 & 3.0 & 3.0 & 2.5 \\
是否安装靠球 & 否 & 否 & 否 & 是 & 是 \\
SG1 $(\mathrm{t})$ & 11.2 & 10.4 & 13.3 & 2.2 & 8.0 \\
SG2 $(\mathrm{t})$ & 3.5 & 2.7 & 3.8 & & \\
SG3 $(\mathrm{t})$ & & 2.3 & 2.7 & & \\
SG4 $(\mathrm{t})$ & & 0.9 & 1.1 & 0.2 & 0.7 \\
XG1 (t) & 1.3 & 1.1 & 1.3 & 0.2 & 0.8 \\
XG2 (t) & 21.0 & 20.2 & 23.5 & 4.0 & 14.5 \\
XG3 (t) & & 3.1 & 3.5 & 0.6 & 2.2 \\
XG4 (t) & & 1.4 & 2.1 & 0.3 & 1.3 \\
\hline
\end{tabular}

通过数据对比, 在相似海况条件下进行外输作业, 安 装靠球后, 靠船件、栈桥及管线作用力明显下降, 油轮靠 泊的撞击力降低约 $60 \%$, 表明靠球的减振效果比较明显。

\subsection{3. 方案优化}

靠球方案使用后，出现如下问题:

(1) 靠球和链条长期浸泡在海水中, 影响使用寿命。 
（2）在油轮靠泊外输过程中，靠球链条及连接件受 油轮横摇影响多次受损。

(3)外输过程中, 链条磨擦靠球表面和 V型橡胶护舷, 并导致一个靠球破损。

考虑靠球的耐久性、维修及冬季使用等方面，对使用 靠球进行优化设计, 在组块 $12 \mathrm{~m}$ 处外扩甲板, 并安装两套 靠球收放装置, 通过该装置在油轮靠泊外输前, 将靠球吊 放到海面, 使用完毕后, 再将靠球回收到甲板上固定。靠 球收放示意图如图（8）所示:

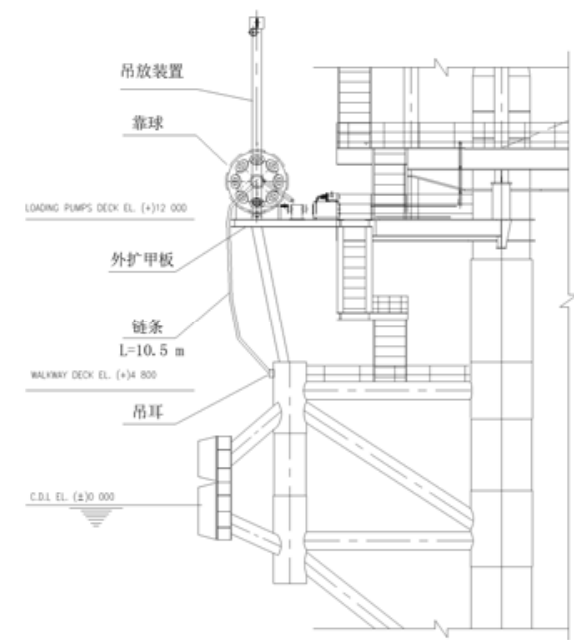

图8 靠球收放装置。

\section{2. 永久性措施}

为避免油轮靠泊的撞击力对平台的影响, 开展了PSP 平台与外输靠船件分离方案设计。分别研究了多个可行方 案并确定了两个方向。如下所示:

方案一：新建 2 座油轮靠泊四腿的导管架平台[9]和2 座筒基系缆平台。

方案二：新建 1 座油轮靠泊八腿的导管架平台 [10]和 1 座桩基系缆平台。

两个方案的技术及费用对比详见表19:

表19 方案对比表。

\begin{tabular}{llll}
\hline 方案名称 & $\begin{array}{l}\text { 钢 材 耗 量 } \\
\text { (吨) }\end{array}$ & $\begin{array}{l}\text { 海上施工 } \\
\text { 难度 }\end{array}$ & $\begin{array}{l}\text { 投资费用 (万 } \\
\text { 元) }\end{array}$ \\
\hline $\begin{array}{l}\text { 2个4腿导管架平台+2筒基 } \\
\text { 系缆平台 }\end{array}$ & 3236 & 较大 & 26,432 \\
$\begin{array}{l}1 \text { 个8腿导管架平台+1桩基 } \\
\text { 系缆平台 }\end{array}$ & 2853 & 较小 & 20,748 \\
\hline
\end{tabular}

从降低投资, 减少钢材用量考虑, 选取方案二做进一 步研究设计。由于PSP平台西侧存在浅断层, 并考虑到火 炬的热辐射等因素, 将新增靠泊平台移至PSP平台东侧。 该方案可避免穿梭油轮直接靠泊PSP平台产生的撞击力对 WHPA平台产生振动 [11]的影响, 优化了系泊形式, 避免 油轮靠、离泊时对系缆平台的撞击风险。此方案总布置图 如图(9)所示:

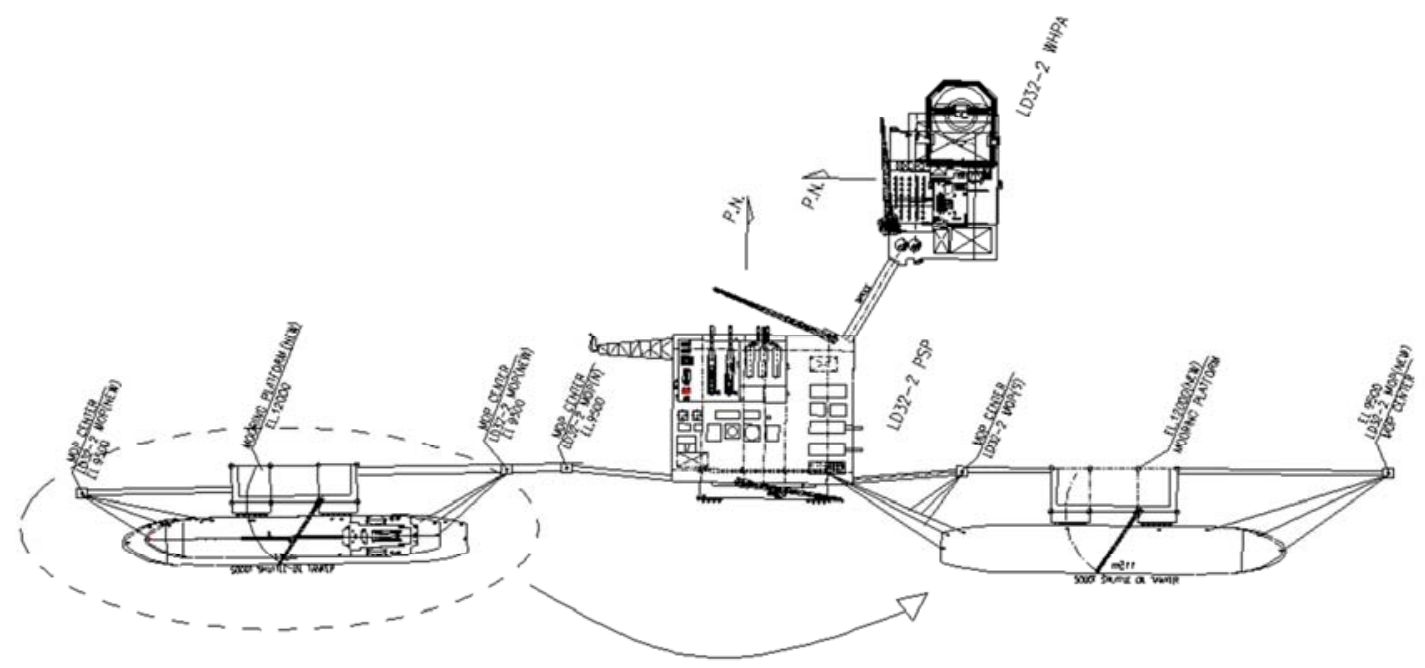

图9 新建靠泊平台示意图。

\section{5. 结束语}

通过对海上油田WHPA平台的振动监测分析 [12]和 WHPA平台振动应对措施[13]的研究, 得出以下几方面结 论: 1、采用直接靠泊型式进行外输作业, 对环境条件有 严格限制, 超出设计限制条件进行外输作业时, 会造成平 台振动。2、油轮靠泊平台产生的撞击力通过栈桥传递到 WHPA平台, 是引起 WHPA平台振动[14]的主要因素。3、 通过实测数据分析, 安装靠球对平台减振起到明显效果,
能够有效的缓解油轮对平台的撞击。4、采用永久性方案 [15]将增加海上外输作业难度, 并增加工程投资。

\section{参考文献}

[1] 范模. 新型生产储油平台总体设计与关键技术 $[\mathrm{J}]$.中国海上 油气.2009年10月, 第5期, 343-346。

[2] 严恺. 海港工程[M].北京：海洋出版社，1996。 
[3] 肖龙飞, 吕海宁. 5000吨油轮靠泊模型试验报告.上海交通 大学.2008年1月。

[4] 胡军, 李长升. WHPA平台振动测试数据分析报告。

[5] 车啸飞, 张大勇, 岳前进, 㚞哲良. 基于实测的导管架海 洋平台振动对人员安全评价 $[\mathrm{J}]$ <<海洋工程 $>>2011$ 年 04 期。

[6] 方新, 陈雪, 王乾, 等. 大位移栈桥管道的设计方案研究 [J]. 石油工程建设.2016，42（3）；6-10。

[7] 胡洪勤. 浅海采油平台振动原因分析及治理措施[J]. 石油工 程建设.2005，31（3）；36-39。

[8] 刘鸿文. 材料力学 $[\mathrm{M}]$. 北京: 高等教育出版社, 2004。

[9] 刘迎春, 张文福, 计静, 陈春砧, 刘嘉. 冰击力下导管架 储油平台动力分析 $[\mathrm{J}]$ < <低温建筑技术 $>>2012$ 年 04 期。

[10] 马网扣, 刘军. 新型立柱式生产储油平台桁架管节点疲劳 分析 $[\mathrm{J}]<<$ 海洋工程装备与技术 $>>2018$ 年04期。

[11] 吕英华, 张文福, 刘迎春, 梁文峰, 谢丹. 导管架储油平 台的自振特性分析 $[\mathrm{J}]<<$ 价值工程 $>>2013$ 年20期。
[12] 付芳, 陆建辉, 李玉辉. 随机波浪载荷下C II 海洋平台结构 可靠性分析[J].石油工程建设.2002，28（6）；5-8。

[13] 唐友刚, 马网扣, 姜大宁. 近海结构振动的智能控制技术 $[\mathrm{J}]$. 石油工程建设.2002，28（6）；5-8。

[14] 王波, 王娜, 霍斌, 徐芹亮. 半潜式钻井平台总体振动研 究 $[\mathrm{J}]<<$ 船舶工程 $>>2011$ 年S1期。

[15] <<海洋石油安全生产规定 $>$.2006年5月1日施行。

\section{作者简介}

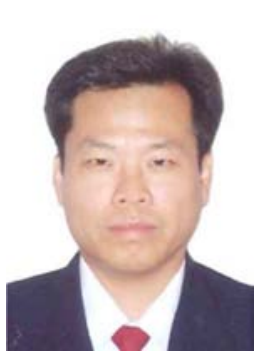

高永（1963-），男，天津人，工程师， 1984年毕业于武汉粮食工业学院机械 加工专业, 现从事海洋石油技术项目管 理工作。 